\title{
Optimalisasi Kenyamanan Thermal Pada Rumah-Rumah Kayu di Kampung Jawa Tondano
}

\author{
Pierre Holy Gosal ${ }^{1}$ \\ Universitas Sam Ratulangi \\ e-mail: pierregosal@gmail.com \\ Vicky Henrie Makarau ${ }^{2}$ \\ Universitas Sam Ratulangi
}

\begin{abstract}
ABSTRAK
Kampung Jawa Tondano adalah suatu permukiman penduduk yang terletak di Kota Tondano. Penduduk Kampung Jawa Tondano adalah keturunan Kyai Mojo dan pengikut-pengikutnya yang berasal dari Pulau Jawa. Kegemaran masyarakat Kampung Jawa Tondano terhadap rumah kayu sehingga saat ini masih banyak sekali rumah kayu berarsitektur Minahasa. Suhu harian Kota Tondano ada pada range $230 \mathrm{C}$ s/d 33 0C dengan kelembaban $80 \%$ s/d $92 \%$. Pada musim panas suhu ekstrim dapat mencapai 350C. Permasalahan yang terjadi adalah rumah-rumah di Kampung Jawa Tondano menjadi tidak nyaman terutama pada siang hari dimana suhu dan kelembaban diatas standar kenyamanan sesuai SNI. Metode penelitian yang digunakan adalah melakukan evaluasi pada selubung bangunan untuk menemukan pada bagian mana dari selubung itu yang memberi kontribusi panas terbesar ke ruangan dan mencari alternatif konstruksi dan material untuk mereduksi perpindahan panas tersebut sehingga suhu ruangan terutama pada siang hari dapat berada dalam range nyaman tanpa harus menggunakan sistem penghawaan buatan. Kalaupun dengan terpaksa harus menggunakan sistem penghawaan buatan, maka akan ditinjau apakah sistem konstruksi cukup memadai untuk dipasangi AC, Fan, dll. Diperoleh melalui kajian bahwa plafond adalah bagian dari bangunan yang memberi kontrubusi panas terbesar, bagian platfond direkayasa dengan menambahkan inovasi-konstruksi tambahan yang dapat menahan panas sehingga berfungsi sebagai insulasi.
\end{abstract}

Kata kunci: rumah kayu, kampung-jawa, minahasa, kenyamanan-thermal, arsitektur

\begin{abstract}
Kampung Jawa Tondano is a residential area located in Tondano Town. The inhabitants of Kampung Jawa Tondano are descendants of Kyai Mojo and his followers who came from Java Island. The society of Kampung Jawa Tondano village against the wooden house is still a lot of wooden houses Minahasa architecture. Daily temperature of Tondano City is in the range of $230 \mathrm{C}$ to $330 \mathrm{C}$ with humidity $80 \%$ to 92\%. In summer the extreme temperatures can reach 350C. The problems that occur are the houses in Kampung Jawa Tondano become uncomfortable especially during the day where the temperature and humidity above the standard in accordance SNI. The method used today is to send to the parts of the envelop that contribute upward and look for alternative constructs and materials to reduce the permanent heat that allows it to be used at the same time in comfortable day spans without having to use artificial guard system. If necessary use artificial guard system, it will be reviewed whether the construction system is adequate enough to be fitted with AC, Fan, etc. The so-called research finds are part of the largest heat building, a part engineered by adding innovation-constructs that can be used as a means.
\end{abstract}

Keywords: wooden house, kampong-java, minahasa, thermal-comfort, architecture

\section{PENDAHULUAN}

Kyai Modjo adalah salah satu panglima dari Pangeran Diponegoro ketika terjadi
Perang Diponegoro atau Perang Jawa yang berlangsung Tahun 1825-1830. Kyai Modjo ditangkap Belanda pada Bulan Nopember

Jurnal Frontiers Volume 1 Nomor 1, April 201891

P-ISSN: 2621-0991 E-ISSN: 2621-1009 
1828 dan bersama pengikut berjumlah 63 orang dibawa sebagai tahanan ke Minahasa pada tahun 1830 dan tiba di Kema, Sulawesi Utara pada Tahun 1830. Hasil identifikai Penelitian memperlihatkan bahwa eksisting Rumah Kayu Minahahasa di kawasan ini sangat banyak mencakup $35 \%$ dari populasi rumah. Suhu dan kelembaban yang relatif tinggi di Kota Tondano terutama pada siang hari sehingga beberapa rumah di Kampung Jawa Tondano memanfaatkan sistem pengkondisian udara buatan yaitu $\mathrm{AC}$ dan Kipas Angin. Rumah-rumah kayu yang ada di Kampung Jawa Tondano tidak direncanakan dengan sistem tata-udara sehingga penggunaan sistem pengkondisian udara adalah cenderung boros energi dan dalam jangka waktu panjang sangat merugikan pemilik rumah.

Rumah-rumah yang ada di Kampung Jawa Tondano beraneka ragam bentuk, gaya dan arsitekturnya. Yang unik pada permukiman ini adalah rumah-rumah yang terbuat dari material kayu sangat menonjol baik bentuknya dan jumlahnya yang berimbang dengan jumlah rumah-rumah beton. Bentuk arsitektur rumah kayu sangat dominan karena sebagian besar rumah ini adalah rumah panggung dibandingkan dengan rumah beton yang sebagian besar berdiri satu lantai diatas tanah. Selain itu, masih terlihat sifat tradisionalnya meskipun dalam banyak hal rumah-rumah kayu ini tidak lagi sama dengan rumah tradisional Minahasa.

Suhu Kota Tondano harian ada pada rentang $230 \mathrm{C} \sim 330 \mathrm{C}$ dengan kelembaban $80 \% \sim 92 \%$. Pada keadaan-keadaan khusus, suhu udara Kota Tondano dapat mencapai nilai ekstrim yakni 350C. Kelembaban yang relatif tinggi di Kota Tondano disebabkan adanya evaporasi danau Tondano. Proses evaporasi air danau karena pemanasan Matahari terjadi secara kontinyu menyebabkan tingkat kelembaban Kota Tondano yang letaknya di sisi danau menjadi sangat tinggi. SNI 03-6572-2001 tentang Tata
Cara Perancangan Sistem Ventilasi dan Pengkondisian Udara pada Bangunan Gedung menjelaskan bahwa daerah kenyamanan termal untuk daerah tropis dapat dibagi menjadi sejuk nyaman, antara temperatur efektif 20,50C 22,80C; nyaman optimal, antara temperatur efektif $22,80 \mathrm{C}$ $25,80 \mathrm{C}$; hangat nyaman, antara temperatur efektif 25,80C 27,10C. 5. Kelembaban Udara Relatif yang dianjurkan untuk rumah antara $40 \% \sim 50 \%$.

Kenyamanan thermal rumah-rumah kayu di Kampung Jawa hanya terjadi pada malam hari, hari, dan sore hari. Pada siang hari sebagaimana hasil tinjauan awal di Kampung Jawa, masyarakat yang tinggal didalam rumah kayu merasa gerah dan panas. Keadaan ini terjadi ketika matahari telah mendekati titik zenith sampai pada sore hari menjelang maghrib atau mulai sekitaran Jam 11.00 siang s/d Jam 16.00 Sore. Beberapa upaya untuk mengatasi keadaan tidak nyaman ini adalah dengan membuka daun jendela lebar-lebar dan membiarkan angin masuk dan meresirkulasi udara didalam ruangan. Apabila tidak ada angin, beberapa keluarga menggunkan kipas-angin untuk mengairkan udara kedalam rumah. Upaya beberapa masyarakat lebih maju adalah memasang Sistem Penkondisian Udara pada ruanganruangan tertentu.

Tujuan Penelitian ini adalah menemukan inovasi konstruksi termasuk model konstruksi insulasi-udara yang tepat untuk diterapkan pada konstruksi selubung rumah-rumah kayu di Kampung Jawa Tondano. Tujuan penelitian ini juga adalah untuk mengkaji secara keseluruhan struktur dan konstruksi rumah-rumah kayu di Kampung Jawa Tondano agar dapat menghasilkan modifikasi-kontruksi yang mendukung sistem tata udara sehingga sistem pengkondisian udara yang digunakan akan efektif dan efisien dan tidak membebani penghuni untuk membayar listrik yang lebih tinggi. Hasil penelitian ini dapat direplikasi pada semua 
rumah-rumah kayu di Manado, Bitung, dan Minahasa, karena typologi bentuk dan struktur yang hampir mirip satu dengan lainnya.

Pengkajian kenyamanan thermal ruangan rumah-rumah kayu di Kampung Jawa Tondano akan merujuk konsep kenyamanan thermal dan sistem kontrol thermal dalam bangunan. Perhitungan beban pendinginan ruangan rumah kayu menggunakan formulasi-formulas tertentu. Kenyamanan thermal mencakup yaitu kenyamanan suhu dan kenyamanan kelembababan, Vaughn Bradshaw, PE 2006. Referensi ini membahas tentang Dalam Psychrometric Chart Kenyamanan Thermal ada didalam zone seperti pada gambar berikut. Penggunaan Psychrometric Chart dalam penentuan kapasiatas sistem penghawaan, Grondzik, W, et all 2010.

Katipamula, et all 2005, mengusulkan tentang sistem pengkondisian udara terbaru dan aplikasinya pada bangunan dimana sistem ini sangat ekonomis terhadap energi dan ramah lingkungan. Disini banyak memberikan pandangan-pandangan berkenan dengan model-model sistem yang konvensional serta mempromosi sistem yang baru. Garrison, R. A., Robertson, L. D., Koehn, R. D., \& Wynn, S. R. (1993) mengumakakan bagaiman Sistem Pengkondisian Udara dapat menyebabkan berkembang-biak jamur membuka wawasan baru terhadap penggunaan material bangunan. Karena material bangunan sangat menentukan gradien suhu dan perpindahan panas sehingga setiap elemen material bangunan perlu diperiksa dan diteliti kemampuannya sebagai iunsulator untuk menahan aliran panas yang melaluinya.

Sangkertadi, 2014 berkesimpulan bahwa suhu nyaman Manado adalah $290 \mathrm{C}$ dengan RH (kelembaban) $60 \%$. Hasil ini 2,1 lebih diatas dari teori yang bersumber dari ASHRAE. Dibandingkan dengan tabel comfort-zone (Hari Yurismono, 2015) diperoleh: Suhu (temperature) adalah 220C s/d 27 OC sementara Kelembaban (RH) adalah $40 \%$ s/d $60 \%$.

$$
\text { Peratuiran Menteri Keseharan }
$$

NO.261/MENKES/SK/II/1998

memperlihatkan bahwa "penyehatan suhu ruangan yaitu : $18^{\circ} \mathrm{C}-26^{\circ} \mathrm{C}$ ". Sementara Gan G (1998) menguraikan bahwa "Suhu udara akan menentukan kecepatan panas yang akan hilang sebagian besar secara konveksi diatas $98^{\circ} \mathrm{F}$, aliran udara berbalik dan akan mendapat panas dari udara, jangkauan kenyamanan untuk sebagian besar orang $89 \%$ bisa mencapai hingga $68^{\circ} \mathrm{F}\left(20^{\circ} \mathrm{C}\right)$ di musim dingin dan $78^{\circ} \mathrm{F}\left(25.5^{\circ} \mathrm{C}\right)$ pada musim panas. Standar kenyamanan termal untuk kelembapan udara yang sering digunakan yaitu Lippsmeir (1994) menyatakan "kelembapan udara relative yaitu $20-50 \%$. Dibandingkan dengan Peraturan Kementerian Kesehatan MENKES (1998) menyatakan kelembapan udara yang sehat itu yaitu $40 \%$ $60 \%$. SNI (1993) menyatakan daerah kenyaman termal padsa bangunan yang dikondisikan untuk orang Indonesia yaitu 40 $\%-70 \%$. Sehubungan dengan beraneka ragamnya standar suhu dan kelembaban ruang, maka dalam peneltian ini digunakan Standar Nasional Indonesia yaitu SNI-141993-03 yaitu antara temperatur sebagai berikut: Sejuk nyaman, antara suhu efektif $20.8^{\circ} \mathrm{C}-22.8^{\circ} \mathrm{C}$, Nyaman optimal antara suhu efektif $22.8{ }^{\circ} \mathrm{C}-25.8^{\circ} \mathrm{C}$, Hangat nyaman, antara suhu efektif $25.8{ }^{\circ} \mathrm{C}-$ $27.1^{\circ} \mathrm{C}$ dengan kelembaban atau $\mathrm{RH}$ (Relative Humidity) $40 \%-70 \%$.

Prianto dan Dwiyanto (2012) dalam publikasi penelitian mereka berjudul Profil Penutup Atap Genteng Beton dalam Efesiensi Konsumsi Energi Listrik pada Skala Rumah Tinggal, memberikan suatu gagasan bagaimana melakukan efisiensi energi dari penutup atap genteng. Metode penelitian yang memberi inspirasi untuk melakukan kajian pada rumah kayu di kampung Jawa. Susilowati dkk (2014) telah megkaji 
Pengaruh Penerapan Arsitektur Tropis Terhadap Kenyamanan Termal Pada Bangunan Publik Menggunakan Software Ecotech Studi Kasus: Perpustakaan Universitas Indonesia. Dalam kajian Susilowati banyak membahas tentang kenyamanan thermal pada bangunan publik dengan menggunakan software. Metode mereka dapat dijadikan pembanding dalam kajian kenyamanan therma bangunan rumah tinggal di Kampung Jawa Tondano. Didalam Pasal 21 UUBG No, 28/2002, Persyaratan kesehatan bangunan gedung sebagaimana dimaksud dalam Pasal 16 ayat (1) meliputi persyaratan sistem penghawaan, pencahayaan, sanitasi, dan penggunaan bahan bangunan gedung. Sedangkan dalam UUBG Pasal 22 ayat (1)menjelaskan bahwa Sistem penghawaan sebagaimana dimaksud dalam Pasal 21 merupakan kebutuhan sirkulasi dan pertukaran udara yang harus disediakan pada bangunan gedung melalui bukaan dan/atau ventilasi alami dan/atau ventilasi buatan. (2) Bangunan gedung tempat tinggal, pelayanan kesehatan, pendidik-an, dan bangunan pelayanan umum lainnya harus mempunyai bukaan untuk ventilasi alami. (3) Ketentuan mengenai sistem penghawaan sebagaimana dimaksud dalam ayat (1) dan ayat (2) diatur lebih lanjut dengan Peraturan Pemerintah. Rifai, Listya Dewi (2014), dalam publikasi mereka berjudul Analisis Intensitas Radiasi Matahari di Manado dan Maros memberikan sebuah masukan yang sangat signifikan dalam pembahasan penelitian ini sebab karya ilmiah ini menjelaskan tentang intensitas radiasi matahari di Manado.

Heinz Frick, (2004) menjelaskan tentang pengetahuan dasar kayu, konstruksi struktur kayu, konstruksi pelindung terhadap cuaca, konstruksi perlengkapan bangunan, konstruksi jembatan kayu dan bekisting beton. Dari sini dapat dipahami tentang perilaku kayu sebagai bahan bangunan yang dalam faktanya Rumah Kayu menggunakan lebih dari $70 \%$ materialnya adalah kayu.
Sifat-sifat fisik kayu dan spesifikasi material juga dapat dipahami sehinggga dengan buku ini dapat menjadi bahan pemikiran dalam melakukan kajian dan analisis selama penelitian.

\section{METODE}

Metodologi yang digunakan adalah metode sistematis. Metode ini adalah merumuskan masalah muncul karena adanya pengamatan dari suatu gejala-gejala yang ada di lingkungan dalam hal ini rumah-rumah tinggal yang terbuat dari kayu di Kampung Jawa. Mengumpulkan informasi yang mengarah dan dekat pada pemecahan masalah termasuk buku-buku referensi dan penelitian-penelitian sebelumnya termasuk. Merumuskan hipotesis atau jawaban sementara yang disusun berdasarkan data atau keterangan yang diperoleh selama observasi atau telaah pustaka.Melakukan pengujianpengujian terhadap hipotesis dengan melakukan percobaan atau penelitian. Melakukan analisis pada data-data temperatur dan kelembaban lingkungan dan interior rumah serta perhitungan-perhitungan untuk menghasilkan kesimpulan. Penarikan kesimpulan ini berdasarkan pada analisis data-data penelitian. Kesimpulan akan dievaluasi 2 atau 3 kali untuk meyakinkan kebenaran hasil penelitian ini. Hasil penelitian ini adalah model konstruksi rumah kayu yang mendukung tata-udara. Model yang dihasilkan konstruksi dinding dan atap rumah kayu lokal tetapi kedap udara. Sistem ventilasi yang mendukung ventilasi alami tapi juga mendukung sistem pengkondisian udara. Cara mengaplikasi sealent yang tepat pada sistem konstruksi kayu lokal, sealent adalah bahan yang dapat melekat pada dua permukaan dan mengisi ruang di antara itu sebagai pembatas atau lapisan pelindung. Sealent digunakan untuk mengisi celah untuk menjaga agar udara keluar. Konstruksi jendela dan pintu lokal yang dimodifikasi agar 
dapat mendukung sistem pengkondisian udara.

\section{HASIL DAN PEMBAHASAN}

Kampung Jawa ini memiliki luas +/- 25 HA dengan jumlah penduduk 2527 orang ( 576 KK). Kawasan ini datar, tidak berkontour dan sebelah utara berbatasan dengan Desa Tonsea Lama sebelah timur berbatasan dengan Perkebunan dan perbukitan Merawas, sebelah selatan berbatasan dengan Sungai Sumasempot, sebelah barat dengan Sungai Tondano (Gambar 1).

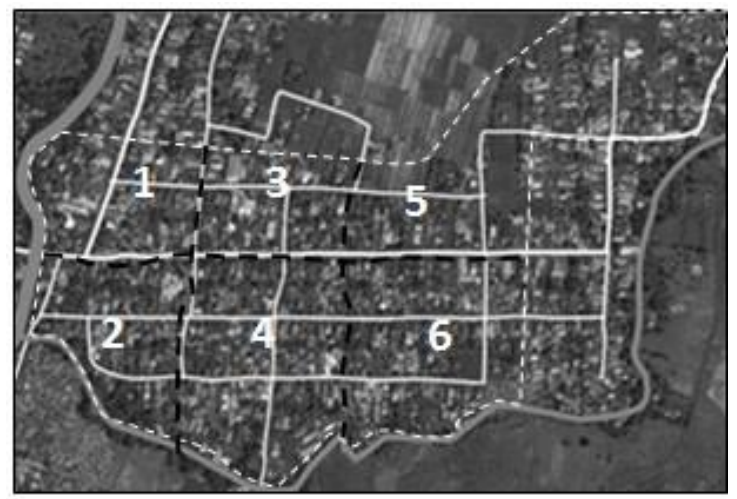

Gambar 1. Kawasan Kampung Jawa Tondano 2014 (Sumber: Citra Google Earth)

Kyai Modjo menetap di Desa Tonsea Lama di-tempat yang bernama Kawak (sebelah timur sungai Ranowangko). Pemerintah Kolonial menempatkan Kyai Modjo dan pengikutnya dalam sebuah bangsal tentara. Lokasi ini dianggab sebagai tempat tinggal kurang layak yang salah satu penyebabnya adalah gangguan dari hewan ternak penduduk lokal. Umar Pulukadang (1978:71) Tahun 1831 bertepatan dengan bulan haji sekitar bulan Mei, Kyai Modjo berpindah ke tempat yang baru yaitu tempat sampai sekarang ini ditempati.

Untuk menetapkan lokasi yang tepat dan sehat untuk permukiman maka Kyai Mojo membuat empat buah "anca" (sosiru) yang terbuat dari nyiru (anyaman bambu) dan masing-masing anca diisikan segumpal daging sapi, kemudian keempat anca ini diikatkan pada empat ujung bambu dan ditancapkan dikeepat penjuru sesuai batas batas yang telah ditentukan oleh Kontroler Belanda.

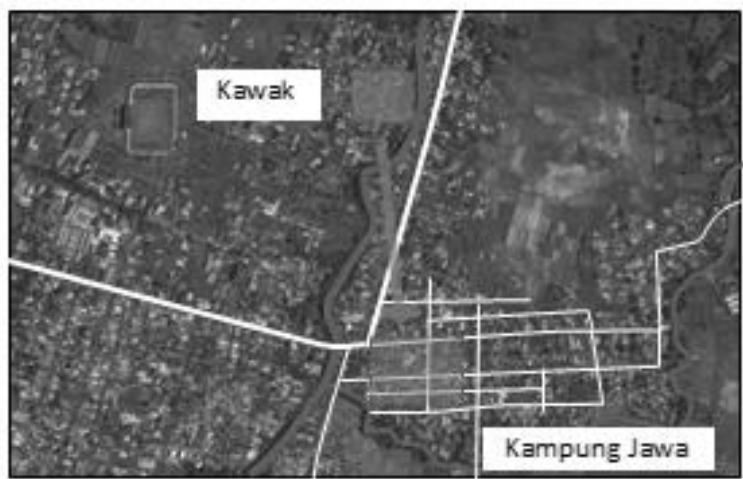

Gambar 2. Dari Kawak berpindah ke Kampung Jawa

(Sumber: Citra Google Earth)

Anca pertama diletakan dikaki pegunungan Masarang. Anca ke-2 dipancang disudut delta yang diapit kali Sumesempot sebelah Selatan dan di Barat Sungai Tondano. Anca ke-3 di Kompleks makam Kyai Mojo sekarang, dan anca ke4 disebelah Timur Tonsea Lama. yang tahan lama membusuk adalah daging dilokasi delta yang diapit oleh kali Sumesempot dan Sungai Tondano itu. Maka diputuskanlah ditempat itu untuk pembangunan Desa yang sekarang menjadi desa Kampung Jawa (Gambar 2). 
Tabel 1 Pertumbuhan Populasi Kampung Jawa Tondano

\begin{tabular}{ccccl}
\hline Tahun & $\begin{array}{c}\text { Jmlh } \\
\text { Pddk }\end{array}$ & $\begin{array}{c}\text { Proyeksi } \\
\text { KK }\end{array}$ & $\begin{array}{c}\text { Proyeksi Jmlh } \\
\text { Rumah }\end{array}$ & \multicolumn{1}{c}{ Keterangan } \\
\hline 1830 & $60+$ & & & Semuanya Pria di Kawak \\
\hline 1831 & 70 & 12 & 10 & Dari Kawak pindah ke Kampung Jawa \\
\hline 1846 & 273 & 46 & 32 & Kyai Modjo meninggal Des 1849 \\
\hline 1854 & 315 & 53 & 37 & \\
\hline 1902 & 1300 & 217 & $\mathbf{1 5 2}$ & Sumber: Carpentier Alting 1902:135 \\
\hline 1965 & 2015 & 336 & $\mathbf{2 3 5}$ & Sumber: Usman Wonopatih dari Kec. Tondano \\
\hline 1970 & 1821 & 304 & $\mathbf{2 1 2}$ & Sumber: Usman Wonopatih dari Kec. Tondano \\
\hline 1975 & 2105 & 351 & $\mathbf{2 4 6}$ & Sumber: Usman Wonopatih dari Kec. Tondano \\
\hline 1976 & 2120 & 353 & $\mathbf{2 4 7}$ & Sumber: Usman Wonopatih dari Kec. Tondano \\
\hline 2008 & 1980 & 440 & $\mathbf{3 3 0}$ & Kecamatan Dalam Angka \\
\hline 2009 & 2016 & 448 & $\mathbf{3 3 6}$ & Kecamatan Dalam Angka \\
\hline 2010 & 2135 & 474 & $\mathbf{3 5 6}$ & Kecamatan Dalam Angka \\
\hline 2011 & 2220 & 493 & $\mathbf{3 7 0}$ & Kecamatan Dalam Angka \\
\hline 2012 & 2410 & 536 & $\mathbf{4 0 2}$ & Kecamatan Dalam Angka \\
\hline 2013 & 2527 & 576 & $\mathbf{4 3 2}$ & Kecamatan Dalam Angka \\
\hline
\end{tabular}

Sumber: Tim Babcock \& Hasil Analisis

Penduduk Kampung Jawa membangun lay-out Kampung Jawa Tondano dengan penataan jalan dan kaveling yang baik. Bentuk eksterior rumah bergaya arsitektur Minahasa tapi didalamnya tinggal Keluarga yang berasal dari Jawa. Salah seorang tokoh muda disini, Wahid Koesasih, ST menjelaskan bahwa Kyai Baderan adalah yang memimpin pembangunan Masjid Kampung Jawa (Masjid Alfallah). Mihrab dibuat oleh Kyai Koesasih. Setelah menjadi Desa Kampung Jawa, pembangunan dipimpin oleh Kepala Desa. Pendekatan untuk dapat menduga lay-out kawasan yaitu dengan memperhitungkan jumlah penduduk Kampung Jawa. Jumlah penduduk yang diketahui dibahagi dengan 6 rata-rata jumlah setiap keluarga karena setiap keluarga di Minahasa tahun 1800an memiliki rata-rata 4 orang anak. Dari jumlah KK diasumsi bahwa $70 \%$ memiliki rumah (Tabel 1). Dari hasil survey dapat diduga bahwa luas kaveling adalah 800 M2 dengan dimensi $20 \mathrm{M} \mathrm{x}$ $40 \mathrm{M}$.
Berdasarkan pendekatan jumlah KK dan arah perkembangan permukiman Kampung Jawa, maka berdasarkan perkembangan KK dan Jumlah Rumah dapat dibuat suatu dugaan (hypotesis) tentang situasi permukiman Kampung Jawa. Dinamika ekspansi permukiman karena bertambahnya penduduk terjadi terus-menerus. Pertumbuhan penduduk Kampung Jawa seiring dengan bertambahnya rumah penduduk. Dengan Masjid Alfallah sebagai pusat pemukiman, kepadatan persebaran rumah yang terpadat (Gambar 3) pada pada arah A dan B, populasi jumlah rumah disini relatif lebih banyak dengan tanah yang makin mengecil. Pada arah $\mathrm{C}$, kepadatan rumah cenderung lebih sedikit dari A dan B tetapi masih lebih banyak dari D. Berdasarkan pola ini akan dilakukan pendugaan perkembangan kawasan permukiman dari waktu ke-waktu (Gambar 4 s/d Gambar 9). 


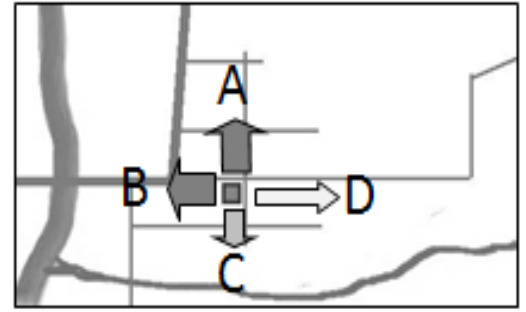

Gambar 3. Pola Perkembangan Kawasan Permukiman Kampung Jawa Sumber: Hasil Analisis
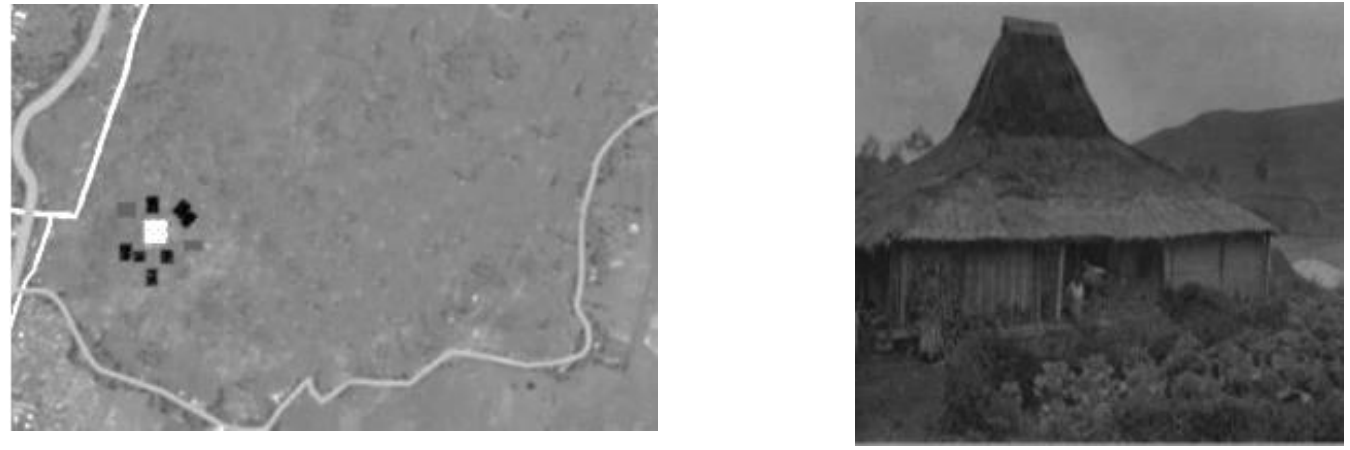

Gambar 4. Tahun 1831 - Arsitektural Visual Saat Pindah dari 'Kawak' (Sumber foto: Internet)
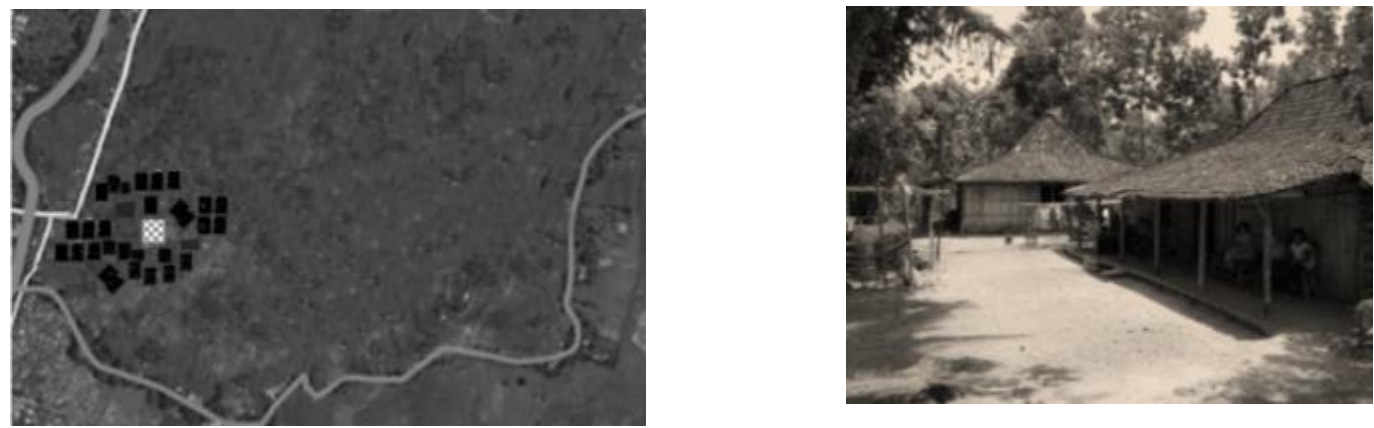

Gambar 5. Tahun 1846 s.d 1856 - Arsitektural Visual N Grafland Tahun 1889 (Sumber foto: Internet)
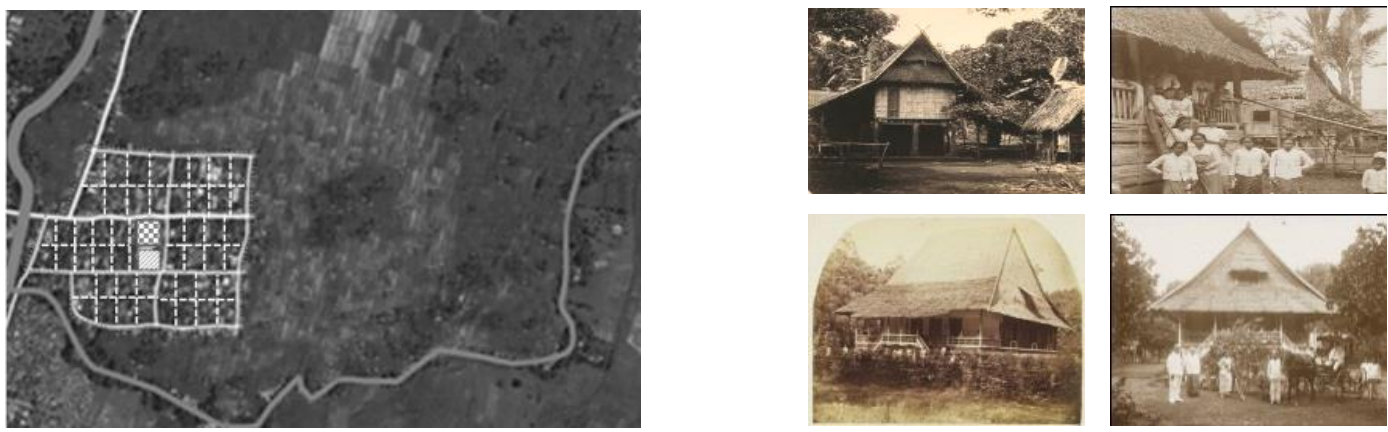

Gambar 6. Tahun 1854-1859 Arsitektur Visual di Era Resident Jansen (Sumber foto: www.kitlv.nl)

Tim G. Babcok (1989) yang mengutip berkomentar bahwa tempat tinggal N Graafland (1869): mengatakan pada kelompok Kyai Modjo dengan bentuk1846 komisaris untuk Manado bentuk gaya Rumah Jawa dan Masjid

Jurnal Frontiers Volume 1 Nomor 1, April 201897

P-ISSN: 2621-0991 E-ISSN: 2621-1009 
dibangun dari bambu dengan atap rumbia. Untuk memahami Kampung Jawa pada tahun 1831 dibuat visual arsitektural, fasade rumah rakyat di Jawa dijadikan pembanding (Gambar 4 dan Gambar 5). Keadaan tersebut berlangsung terus sampai dengan sekitar Tahun 1856 ketika Kommisaris Pemerintah Belanda untuk Manado membuat laporannya. Tim Babcock juga mengutip laporan P. Bleeker (1856) yang mengatakan bahwa Kampung Jawa kelihatan seperti Kampung yang berada di Jawa.

Pada masa Residen Jansen (18531859), penduduk Kampung Jawa diperintahkan untuk membangun rumah yang baik dengan lay-out kampung yang baik. N. Grafland (1869) mencatat bahwa siapapun yang melihat Kampung Jawa tidak ragu bahwa Kampung Jawa adalah Kampung Minahasa yang dihuni oleh masyarakat berasal dari Jawa. Dari pengertian ini maka Kampung Jawa dianggap mirip dengan Kampung di Minahasa, dan bentuk-bentuk fasade rumah di Kampung Jawa mirip dengan rumah-rumah di Kampung Minahasa lainnya. Visualisasi fasade-fasade rumah di Kampung Jawa pada era tersebut dibuat (Gambar 6). Jessy Wenas (2007:119) rumah tradisional itu ada 2 type: 'wale wangko' dan 'rumah tinggal'. Walewangko adalah rumah yang ditutup atap rumbia dengan dinding papan dan rumah panggung. DR Bleeker (1856) mengatakan bahwa rumah-rumah di Minahasa didirikan diatas tiang tinggi dan besar yang dihuni 4 keluarga. Rumah-rumah besar baik yang sumbu sejajar jalan dan tegak-lurus jalan adalah pengembangan dari 'wale-wangko' (Gambar 7).

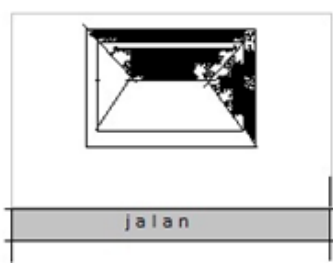

A

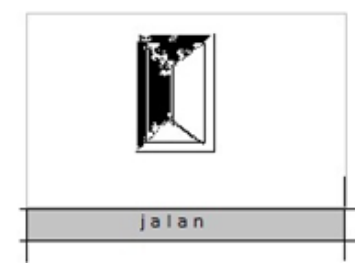

B
Gambar 7. Rumah Tradisional Type Sejajar Sumbu Jalan (A) dan Tegak Lurus (B)

Pada era 1902-1952. mayoritas populasi rumah di Kampung Jawa dibangun dalam bentuk rumah panggung dengan sumbu atap tegak-lurus jalan dan simetris. Era kejayaan rumah tinggal tradisional Minahasa ada pada era ini. Ciri khas rumah ini terletak pada atap, tangga dan rumah ini bertumpu pada balok besar diatas umpak beton atau batu alam (Gambar 8).

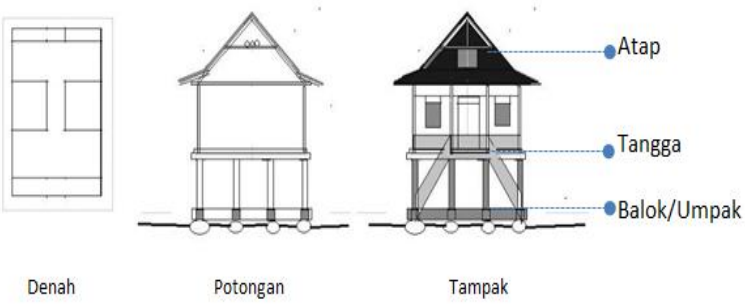

Gambar 8. Typical Rumah Tinggal Tinggal Tradisional Minahasa di Kampung Jawa 

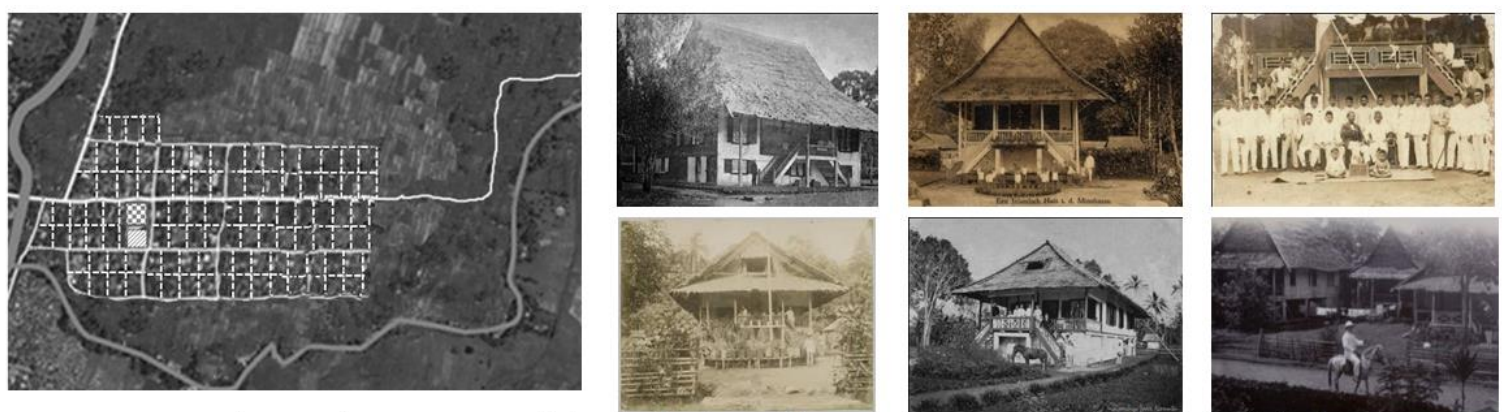

Gambar 9. Tahun 1902-1952 Arsitektural Visual Permukiman Kampung Jawa

(Sumber foto: www.kitlv.nl)
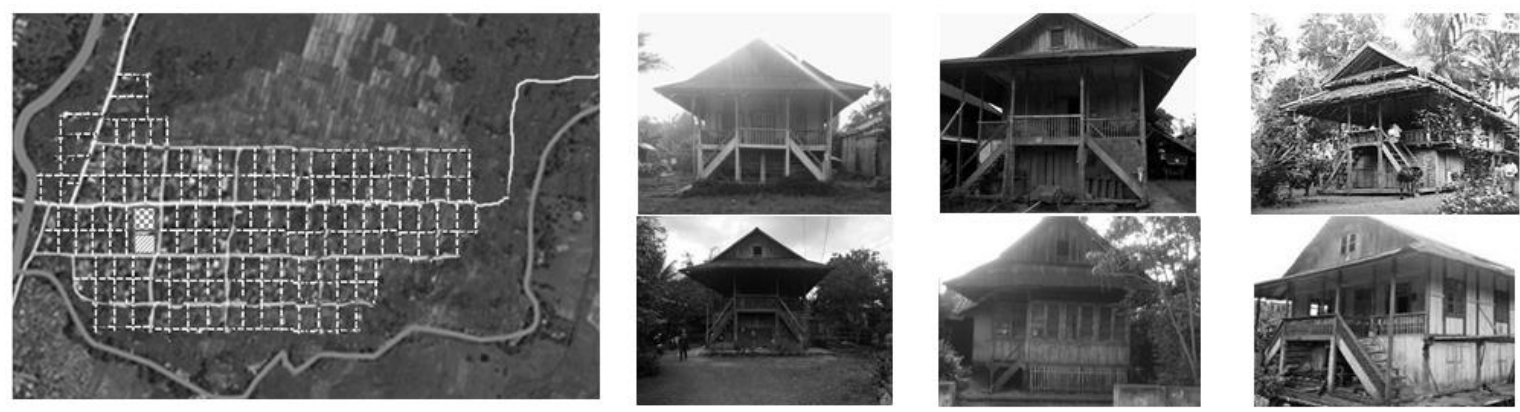

Gambar 10. Tahun 1965 Arsitektural Visual Permukiman Kampung Jawa (Sumber foto: www.kitlv.nl)
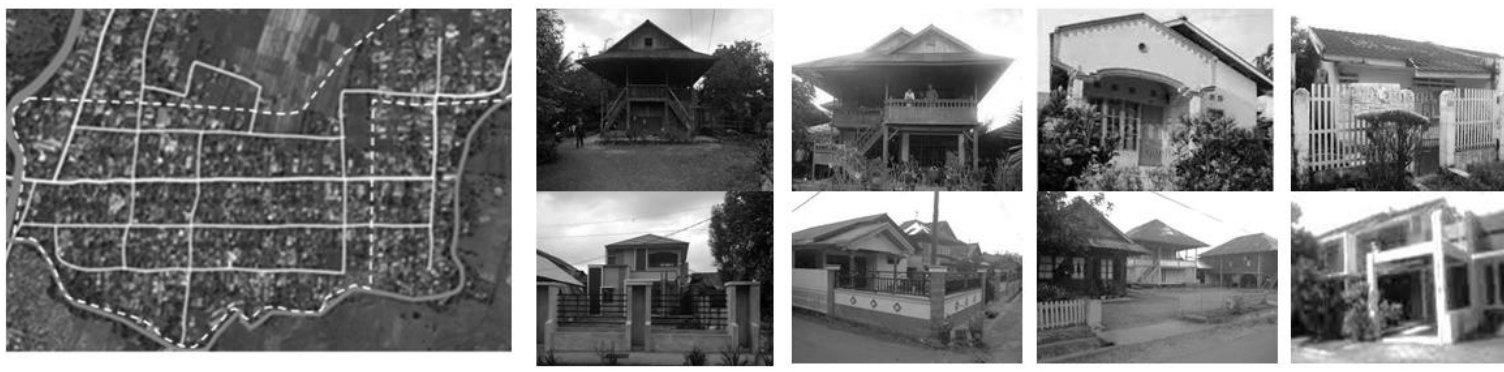

Gambar 11. Tahun 2014 Permukiman Kelurahan Kampung Jawa Tondano Citra Google Aerth 2014

(Sumber foto: hasil analisis)

Kenyamanan Thermal adalah suatu kondisi thermal yang dirasakan oleh manusia, bukan oleh benda, binatang, dan arsitektur, tetapi dikondisikan oleh lingkungan dan benda-benda disekitar arsitekturnya atau kondisi pikir seseorang yang mengekspresikan kepuasan dirinya terhadap lingkungan thermalnya. Tri Harso Karyono (2010) menjelaskan bahwa dalam teori kenyamanan termal dinyatakan bahwa rasa panas atau dingin yang dirasakan oleh tubuh manusia sesungguhnya merupakan wujud respon dari sensor perasa yang terdapat pada kulit terhadap stimuli suhu yang ada di sekitarnya. Sensor perasa berperan menyampaikan informasi rangsangan raa kepada otak di manan otak akan memberikan perintah kepada bagianbagian tubuh tertentu agar melakukan antisipasi guna mempertahankan suhu tubuh agar tetap berada pada sekitar $37^{\circ} \mathrm{C}$, di mana hal ini diperlukan agar organ dalam tubuh dapat menjalankan fungsinya secara baik. Standar Internasional (ISO 7730:1994) menyatakan bahwa sensasi termis yang dialami manusia merupakan fungsi dari empat faktor iklim yakni, suhu 
udara, suhu radiasi, kelembaban udara, kecepatan angin, serta dua faktor individu yakni, tingkat aktifitas yang berkaitan dengan laju metabolisme tubuh, serta jenis pakaian yang dikenakan.

Standar ISO 7730 menyatakan bahwa kenyamanan termal tidak dipengaruhi secara nyata oleh hal-hal lain misalnya, perbedaan jenis kelamin, tingkat kegemukan, faktor usia, suku bangsa, adaptasi, tempat tinggal geografis, faktor kepadatan, warna, dan sebagainya. Salah satu hal yang menonjol dari teori Fanger adalah dihasilkannya suatu rumusan bahwa 'kenyamanan termal' merupakan fungsi dari 4 (empat) faktor iklim (climatic factors) yakni: suhu udara $\left({ }^{\circ} \mathrm{C}\right)$, suhu radiasi $\left({ }^{\circ} \mathrm{C}\right)$, kelembaban udara $(\%)$ dan kecepatan angin $(\mathrm{m} / \mathrm{s})$, serta fungsi dari 2 (dua) faktor individu yakni: jenis aktifitas (yang dinyatakan dengan laju metabolisme tubuh, met) serta jenis pakaian (yang dinyatakan dalam unit clo) yang dikenakan oleh seseorang.

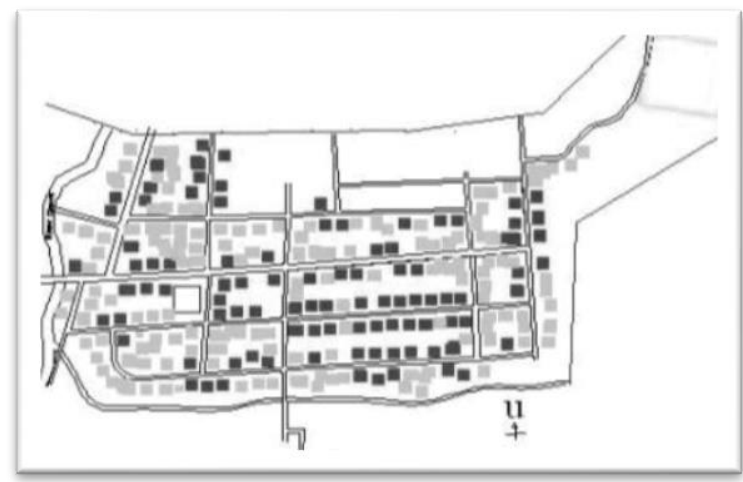

Gambar 12. Persebaran Rumah Kayu Minahasa di kampung Jawa Tondano

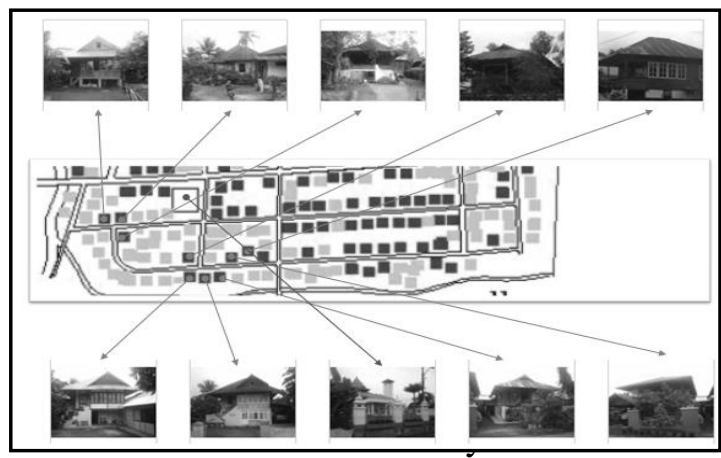

Kampung Jawa

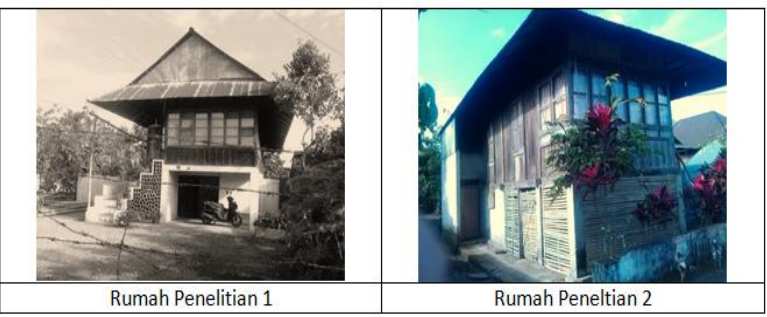

Gambar 14. Dua Buah Rumah Kayu di Kampung Jawa Tondano Yang dijadikan Obyek Penelitian

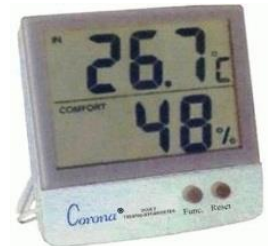

Gambar 15. Thermohygrometer yang Digunakan 
Tabel 1

Kesimpulan Rata-Rata Suhu dan Kelembaban Haria pada 2 Buah Rumah Peneltian

\begin{tabular}{|c|c|c|c|c|c|c|}
\hline \multirow[t]{2}{*}{ JAM } & \multicolumn{3}{|c|}{ SUHU } & \multicolumn{3}{|c|}{ RH } \\
\hline & Posisi I & Posisi II & ${ }^{0} \mathrm{C}$ & Posisi I & Posisi II & $\%$ \\
\hline 05.00 & 22.1 & 22.4 & ${ }^{0} \mathrm{C}$ & 76.7 & 76.7 & $\%$ \\
\hline 06.00 & 22.8 & 23.1 & ${ }^{0} \mathrm{C}$ & 74.0 & 75.5 & $\%$ \\
\hline 07.00 & 23.8 & 24.2 & ${ }^{0} \mathrm{C}$ & 75.1 & 78.3 & $\%$ \\
\hline 08.00 & 24.8 & 25 & ${ }^{0} \mathrm{C}$ & 71.8 & 73.0 & $\%$ \\
\hline 09.00 & 26.1 & 26.9 & ${ }^{0} \mathrm{C}$ & 74.7 & 79.0 & $\%$ \\
\hline 10.00 & 27 & 27.5 & ${ }^{0} \mathrm{C}$ & 76.0 & 82.5 & $\%$ \\
\hline 11.00 & 28.1 & 28.7 & ${ }^{0} \mathrm{C}$ & 76.1 & 79.1 & $\%$ \\
\hline 12.00 & 29.4 & 30.1 & ${ }^{0} \mathrm{C}$ & 76.0 & 74.5 & $\%$ \\
\hline 13.00 & 31.1 & 31.6 & ${ }^{\circ} \mathrm{C}$ & 75.6 & 76.9 & $\%$ \\
\hline 14.00 & 30 & 31 & ${ }^{0} \mathrm{C}$ & 78.0 & 77.4 & $\%$ \\
\hline 15.00 & 28.8 & 28.7 & ${ }^{0} \mathrm{C}$ & 77.1 & 79.6 & $\%$ \\
\hline 16.00 & 27.1 & 27.2 & ${ }^{0} \mathrm{C}$ & 77.0 & 77.6 & $\%$ \\
\hline 17.00 & 25.8 & 26.3 & ${ }^{0} \mathrm{C}$ & 72.2 & 76.0 & $\%$ \\
\hline 18.00 & 24.2 & 25 & ${ }^{0} \mathrm{C}$ & 72.0 & 73.4 & $\%$ \\
\hline 19.00 & 23.1 & 24.4 & ${ }^{0} \mathrm{C}$ & 70.5 & 74.8 & $\%$ \\
\hline
\end{tabular}

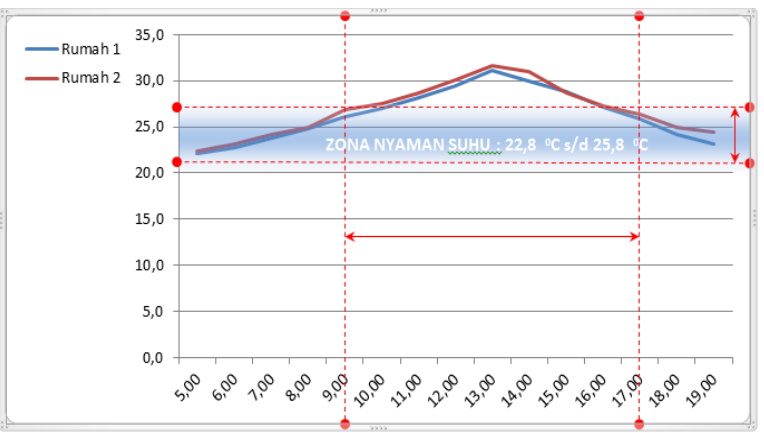

Gambar 16. Grafik Kinerja Kenyamanan Ther Rumah Penelitian

Sesuai hasil kajian Tim Peneliti, bagian dari selubung bangunan yang memberi konstribusi panas kedalam ruangan yang palin signifikan adalah bagian atap. Seperti kita lihat pada 2 buah rumah penelitian bahwa atapnya menggunakan atap seng yang adalah benda logam. Secara umum ada 2 cara untuk mengkondisikan rumah kayu di Kampung Jawa Tondano tetap berada pada Bahan yang digunakan adalah bahan yang tersedia secara lokal dengan sangat banyak yaitu Ijuk Pohon Nipah atau dikenal dengan nama "gomutu" pada Pohon Enau atau Seho.
Zona Nyaman. Yang pertama adalah dengan menggunakan sistem penghawaan udara (AC) dimana hal ini sangat tidak disarankan. Yang kedua dengan melakukan sebua inovasi konstruksi pada konstruksi atap dengan tujuan agar panas matahari yang di transmisikan melalui seng dapat ditahan dibawahnya. Konstruksi yang diajukan adalah menggunakan ijuk dan sebagai insulasi panas. Ijuk ini dipasang tepat dibawah atap seng, diantara kayu gording.
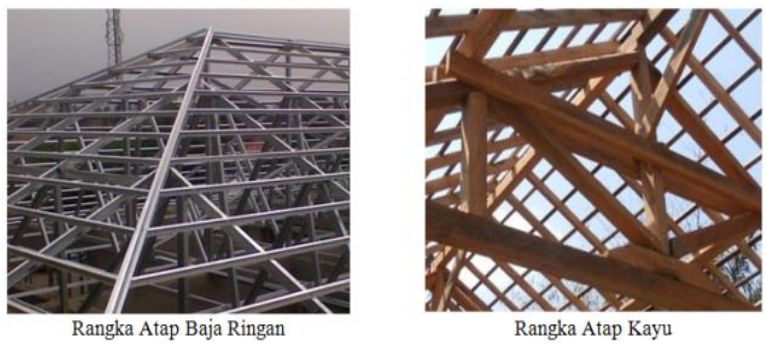

Gambar 17. Rangka Atap Yang Ada di Kampung Jawa Tondano 


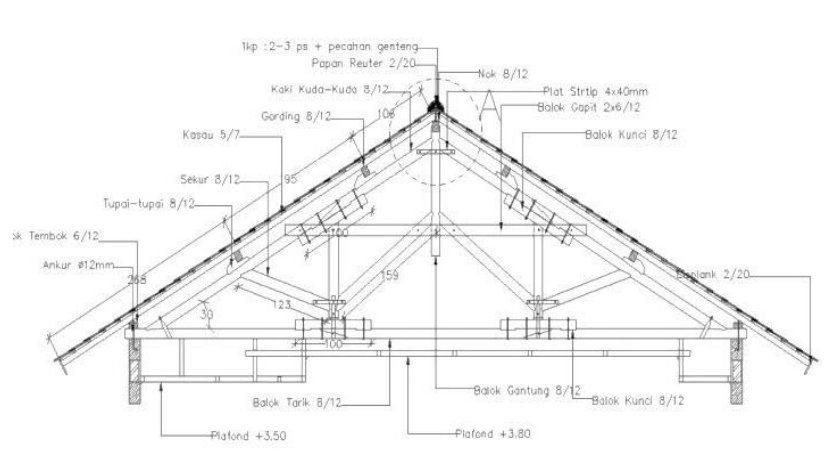

Gambar 18. Potongan Atap dengan Penutup Seng

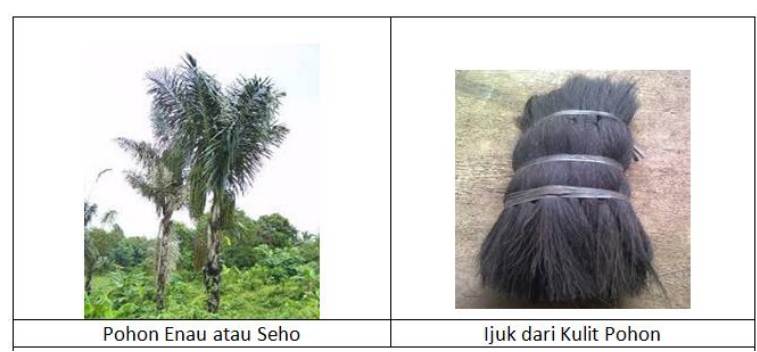

Gambar 19. Pohon Enau dan Ijuk

Prosedur Kerja pemasangan ijuk dibawah seng adalah untuk rumah yang sudah jadi maka diperlukan pemasangan triplex $9 \mathrm{~mm}$ pada bagian bawah Gordin. Setelah tripleks terpasang, buka kembali lembaran seng diatasnya sehingga kelihatan tripleks yang sudah terpasang. Masukan ijuk atau gomutu dengan teratur sampai padat diatas tripleks sampai memenuhi ruang tersebut dan merata pada permukaan dimana seng akan dipasang kembali. Setelah pemasangan merata maka seng diatasnya dipasangkan kembali ketempatnya. Diharapkan ijuk yang terpasang sesuai dengan ketebalan gording atau kalau gordingnya adalah Balok 10/15 maka ketebalan ijuk adalah $15 \mathrm{~cm}$.

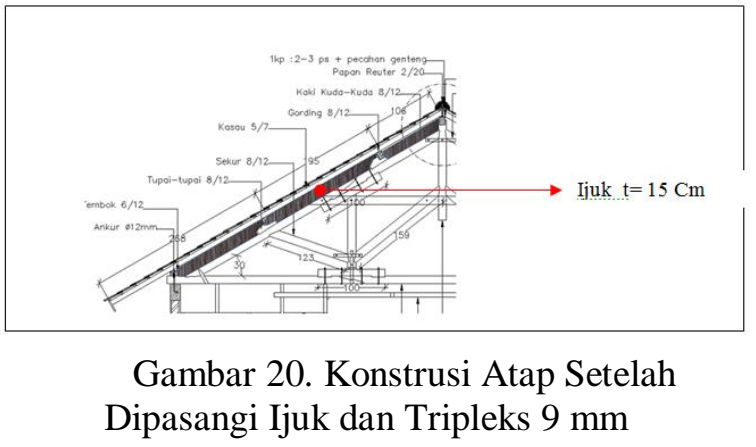

Setelah dipasangi Ijuk pada Rumah Peneltitian, maka terjadi penurunan suhu rumah yang diukur secara harian. Kesimpulan bahwa rata-rata penurunan suhu sebesar 3,25 0C pada rumah-rumah yang diteliti. Ijuk yang dipasang tebalnya $15 \mathrm{Cm}$ pada Rumah 1 dan tebal $8 \mathrm{Cm}$ pada rumah 2 karena rumah 2 tidak menggunakan kuda-kuda tetapi hanya menggunakan Kasau atau Totara. Msekipun demikian penurunan suhu pada dua rumah tersebut hampir sama yaitu $3,25 \mathrm{Cm}$. Sehingga pada waktu puncak Jam 13.00 Suhu ruangan ada pada range 27 0C 28 0C. Penurunan ini meskipun belum mencapai dibawah kondisi nyaman tetapi secara signifikan berhasil.

\section{PENUTUP}

\section{Kesimpulan}

Kesimpulan yang dapat ditarik adalah:

- Atap seng adalah bagian selubung bangunan yang paling besar mengtransmisi panas kedalam ruangan atap dan karena rata-rata material platfond adalah tripleks $3 \mathrm{~mm}$, maka panas seng diradiasikan kedalam ruangan atap dan ditransmisikan kedalam ruangan rumah.

- Keadaan kurang nyaman didalam rumah-rumah kayu di Kampung Jawa Tondano terjadi pada Jam $09.00 \mathrm{~s} / \mathrm{d}$ 11.00 dan Jam $15.00 \mathrm{~s} / \mathrm{d} 17.00$.

- Keadaan tidak nyaman dalam runagb terjadi selang Jam $11.00 \mathrm{~s} / \mathrm{d}$ 15.00. 
- Rumah-rumah kayu di Kampung Jawa Tondano yang ada saat ini perlu dimodifikasi konstruksi atap agar dapat menjaga kinerja kenyamanan thermal sesuai standar SNI.

- Kalau kenyamanan kelembaban ruangan sesuai SNI yaitu $40 \mathrm{~s} / \mathrm{d} 60 \%$ $\mathrm{RH}$, tidak ada jalan lain kecuali menurunkan dengan menggunakan alat dehumidifier tetapi masyaraka Kampunbg Jawa Tondano telah terbiasa dengan keadaan kelembaban tersebut sehingga dalam pertemuan-pertemuan tidak ada yang merasa lembab.

- Inovasi temuan adalah Konstruksi atap ditambahi ijuk atau gomutu dibawah seng dan ditutupi dengan tripleks $9 \mathrm{~mm}$. Dengan melakukan hal ini, dapat menrurnkan panas ruangan atap ratarata $3{ }^{\circ} \mathrm{C}$.

\section{DAFTAR PUSTAKA}

Babcock, T., (1989). Kampung Jawa Tondano, Religion And Cultural Identity, Gajah Mada University Pres, Jogyakarta

Bradhaw V, PE, (2006). The Building Environment: Active and Passive Control System, John Willey \& Sons, New Jersey, USA

Bleeker, P., (1856). Reis door de Minahasa en den Molukschen Archipel, Batavia, Lange

Frick, I. H. (2004). Konstruksi Arsitektur 6 ILMU KONSTRUKSI BANGUNAN KAYU, Pengantar Konstruksi Bangunan (Vol. 6). Kanisius.

Gan, G. (1998). A parametric study of Trombe walls for passive cooling of buildings. Energy and buildings, 27(1), 37-43.
Garrison, R. A., Robertson, L. D., Koehn, R. D., \& Wynn, S. R. (1993). Effect of heating-ventilation-air conditioning system sanitation on airborne fungal populations in residential environments. Annals of allergy, 71(6), 548-556.

Grafland, N., (1869). De Minahasa : Haar Verleden En Haar Tegenwoordige Toestand, M. Wyt \&, Zonen, Rotterdam (Diterjemahkan Oleh Lucy R. Montolalu Edisi II Tahun 1991)

Grondzik W, et all, (2010). Mechanical and Electrical Equipment for Buildings, John Willey \& Sons, New Jersey, USA

Katipamula, S., \& Brambley, M. R. (2005). Methods for fault detection, diagnostics, and prognostics for building systems - a review, part I. Hvac\&R Research, 11(1), 3-25

Lippsmeier, G. (1994). Alih bahasa oleh Ir. Syahmir Nasution, Bangunan Tropis, Penerbit Erlangga. Jakarta.

Pulkadang, R., A., (2008). Sejarah Kampung Jawa Tondano, Jakarta

Haji Ali (2012). Jawa Tondano, http://jawatondano.blogspot.com/ (16 JulI)

Pulukadang, U., (1978). Kyai Madja dan Islam di Minahasa, Jurnal Mimbar Ulama No. 18 Tahun II

Prianto, E., \& Dwiyanto, A. (2013). Profil Penutup Atap Genteng Beton Dalam Effesiensi Konsumsi Energi Listrik Pada Skala Rumah Tinggal. Modul. 
Rahardjo, M,. (1978). Metode Pengumpulan Data Penelitian Kualitatif, UIN Maliki Malang, 2011

Rifai, L. D., Tongkukut, S. H., \& Raharjo, S. S. (2014). Analisis Intensitas Radiasi Matahari di Manado dan Maros. JURNAL MIPA UNSRAT ONLINE, 3(1), 49-52.

Sangkertadi, S., \& Syafriny, R. (2014). New Equation for Estimating Outdoor Thermal Comfort in Humid-Tropical Environment. European Journal of Sustainable Development, 3(4), 4352.

Susilowati, D., \& Wahyudi, F. (2014). Kajian Pengaruh Penerapan Arsitektur Tropis Terhadap Kenyamanan Termal Pada Bangunan Publik Menggunakan Software Ecotech Studi kasus: Perpustakaan Universitas Indonesia. Jurnal Ilmiah Desain dan Konstruksi.

Wenas, J., (2007). Sejarah \& Kebudayaan Minahasa, Institut Seni Budaya, Sulawesi Utara, Manado. 